\title{
Water Pollution Characterization by Pathogenic Indicators in Water Runoff in the Downtown of Hanoi, Vietnam
}

\author{
Pham Van QUAN", Hiroaki FURUMAI**, Futoshi KURISU**, Ikuro KASUGA**, \\ Cao The HA ${ }^{* * * *}$, Le Van CHIEU ${ }^{* * * *}$ \\ * Faculty of Urban and Rural Planning, Hanoi Architectural University, Km 10, Nguyen Trai \\ Road, Thanh Xuan District, Hanoi, Vietnam \\ ** Research Center for Water Environment Technology (RECWET), the University of Tokyo, 7- \\ 3-1 Hongo, Bunkyo-ku, Tokyo 113-8656, JAPAN \\ *** Research Centre for Environmental Technology and Sustainable Development, Hanoi \\ University of Science, 334 Nguyen Trai Road, Thanh Xuan District, Hanoi, Vietnam
}

\begin{abstract}
In Hanoi, the capital of Vietnam, lakes and rivers are polluted by both point pollution sources such as discharge from sewerage system; and by non-point pollution sources such as washoff from land surface and leakage from septic tanks. Several studies had mentioned about water pollution but were mainly focusing on organic pollution, feacal contamination and pollutant sources from surface runoff were not considered. To investigate the characteristics of pollutant variation in runoff water and feacal contamination by pathogenic indicators, water samples were collected in August and September 2008, by the roadside and at the inflows of lakes under wet weather condition in the downtown of Hanoi. Monitoring results showed high pollutant concentration, especially pathogenic indicators as E.coli and total coliform (TC), both in road runoff and water that flowed into lakes. Runoff water quality was much different depending on the sampling locations and patterns of rainfall. Pollutant concentration collected by the roadside tend to increase at the end of rainfall. It might be attributed to the discharge of domestic wastewater from individual households or leakage from septic systems. Time and spatial variation were much different for each event that made urban runoff water to be more difficult to control in comparison with domestic wastewater. Cluster analysis was applied to find the similarities of water quality among sampling locations. It was a useful method to find the spatial variation of pollutants and their level of pollution.
\end{abstract}

Keywords: Hanoi downtown, pathogenic pollution, pollutant variation, runoff water, sewerage system

\section{INTRODUCTION}

Hanoi, the capital of Vietnam, is one of the biggest capitals in the world, with a total area of more than $3,300 \mathrm{~km}^{2}$ and with 6.4 million inhabitants in 2009 . The old sewerage system and the quite flat floodplain make Hanoi more sensitive to urban flood. Frequent inundation causes damages to infrastructure, transportation, environment, and human health. As shown in Fig. 1, the sewerage system is a combined type, which means that both wastewater and runoff water are served by one system. Runoff in urban areas is seen as the major source contributing to water quality degradation in surface water bodies (Gruber et al., 2005).

Non-point source (NPS) pollution, is the contamination of ground water and other water bodies that results from everyday activities. With each rainfall, pollutants generated by these activities are washed into storm drains that flow into waterways. As a result, NPS pollution is the biggest threat to many ponds, creeks, lakes, wells, streams, rivers, bays,

Address correspondence to Pham Van QUAN, Faculty of Urban and rural planning, Hanoi Architectural University, Email: quanrua@gmail.com

Received May 19, 2009, Accepted July 22, 2010. 
and ground water. This NPS pollution resulting from urban surface runoff could be recognized as one of the major causes of quality deterioration in the receiving water bodies (Marsalek and Rochfort, 2004).

During inundation, wastewater and runoff water can possibly flow out of the sewerage system to streets within the downtown of Hanoi as well as to lakes and rivers, because the drainage capacity was designed for the less-developed condition of old Hanoi. It means that most of the outfalls from the sewerage system are seen as a point source pollution to the lakes and rivers in Hanoi both under the dry and wet weather conditions. Point sources are those that can be traced back to a pipe and are one of the largest potential sources of human feacal contamination (O'Keefe et al., 2005). In Hanoi, sewage treatment plants (STP) have not been constructed even though the amount of wastewater has increased sharply in recent years accompanying the rapid industrialization and urbanization. Up to now, only two on-site pilot STPs with a total capacity of $6,000 \mathrm{~m}^{3} / \mathrm{d}$ (around $1 \%$ of the total wastewater produced in Hanoi) are built.

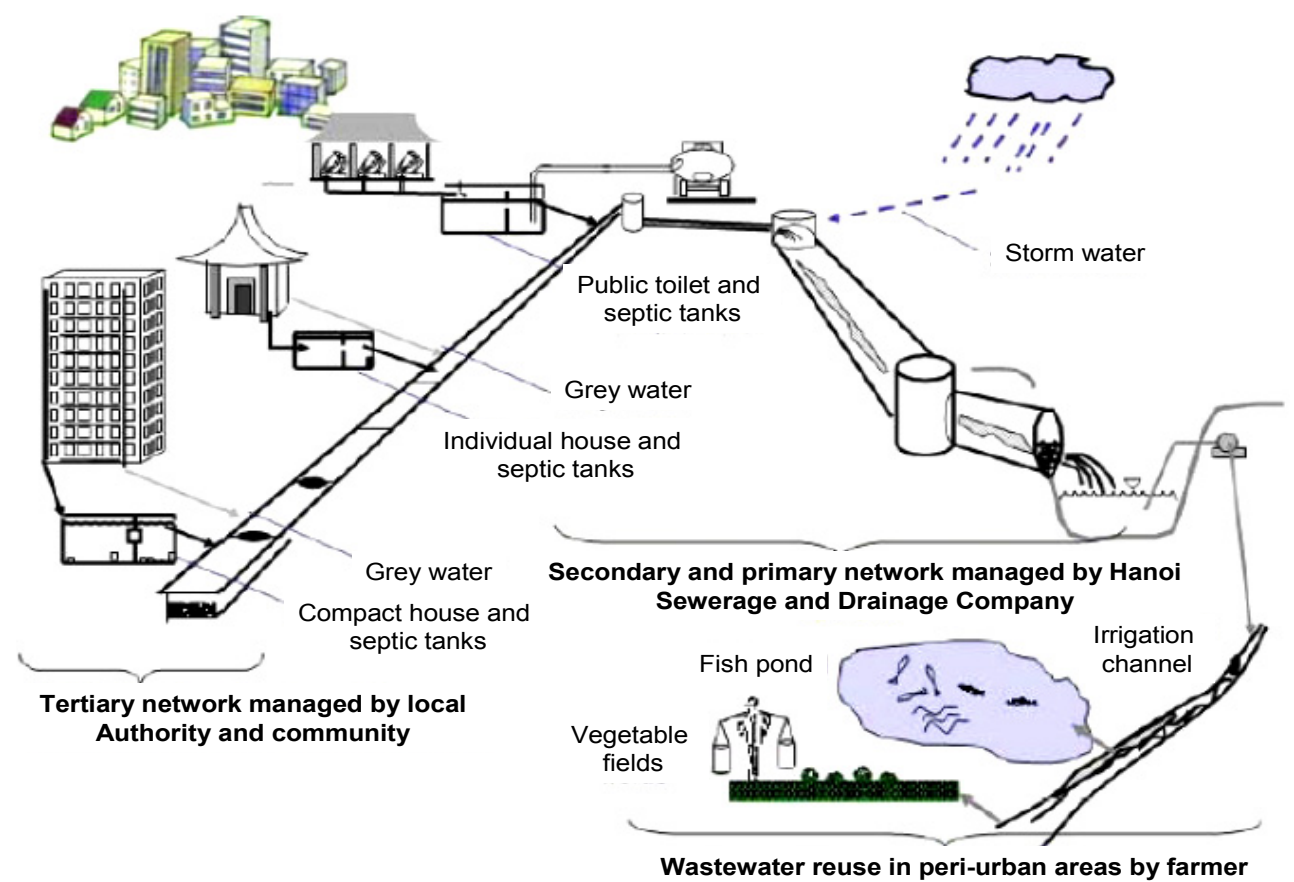

Fig. 1 - Operation of sewerage and drainage system in Hanoi (Anh et al., 2005).

Several monitoring studies of surface water environment were carried out in Hanoi. Ha (2005) reported that the water quality of rivers, lakes, and ponds is worsening due to the discharge of untreated wastewater, which contains toxic substances, inorganic substances, and high organic matter. On the average, concentrations of biochemical oxygen demand (BOD), chemical oxygen demand (COD) and heavy metals in rivers are 3-4 times higher than the standards in Vietnam. Thang et al. (2005) and Quan et al. $(2005,2008)$ studied similar organic pollution, but the feacal contamination and pathogenic pollution were not considered. In addition, these studies did not pay much attention on runoff water quality and its variation. In the present study, runoff water samples were collected in 2008 to obtain deeper understanding regarding the spatial variation and time variation of runoff water quality and the pathogenic pollution under wet weather condition. 


\section{MATERIALS AND METHODS}

With the aim to monitor pathogenic pollution in runoff water, water samples were collected twice in August and September 2008 and the hyetograph of each sampling time is shown in Fig. 2.

Samples were collected during rainy days four times on August 31, 2008 (rainfall 17 $\mathrm{mm}$ ), and two times on September 21, 2008 (rainfall $3 \mathrm{~mm}$ ) at different locations. Sampling locations were the inflows of 3 lakes (Thien Quang (L-TQ in), Bay Mau (L$7 \mathrm{M}$ in), and $\mathrm{Ba}$ Mau (L-3M in)) and 3 streets (Ton Duc Thang (S-TDT), Nguyen Khuyen (S-NK), and Le Duan (S-LD)). All the sampling locations are shown in Fig. 3 and Table 1.

Table 1 - Sampling locations in the downtown of Hanoi

\begin{tabular}{lllrl}
\hline & & \multicolumn{2}{c}{ Locations } \\
\hline \multirow{2}{*}{ No } & \multicolumn{1}{c}{ Sampling Points } & Code/Abbreviation & Latitude & Longitude \\
\hline 1 & Ba Mau lake, inflow & L-3M in & 21.02163 & 105.83874 \\
2 & Bay Mau lake, inflow & L-7M in & 21.01435 & 105.84340 \\
3 & Thien Quang lake, inflow & L-TQ in & 21.01854 & 105.84720 \\
4 & Le Duan street & S-LD & 21.03333 & 105.84000 \\
5 & Nguyen Khuyen street & S-NK & 21.03573 & 105.83639 \\
6 & Ton Duc Thang street & S-TDT & 21.03346 & 105.83193 \\
\hline
\end{tabular}

Note: L- Lake; S- Street; in- inflow to lake
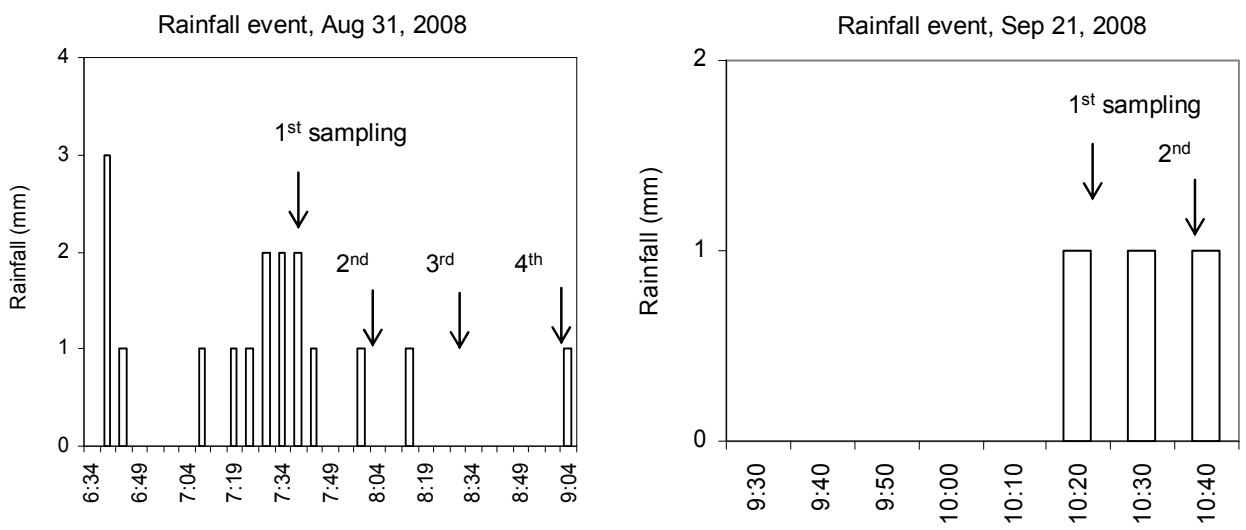

Fig. 2 - Sampling procedure based on hyetograph of rainfall events.

Selected parameters are total nitrogen (T-N), ammonium nitrogen $\left(\mathrm{NH}_{4}{ }^{+}-\mathrm{N}\right), \mathrm{COD}$, suspended solids (SS), electrical conductivity (EC), E.coli and total coliform (TC). The monitoring kit of m-ColiBlue24 Broth is used for simultaneous detection and identification of both TC and E-coli with respect to the level of toxicity to human health upon exposure to runoff water in Hanoi. A sample volume of $1 \mathrm{~mL}$ was used for the monitoring kit with and without dilution.

Water quality was compared with the Vietnamese standard for surface water environment, as seen in Table 2, and with that of a STP influent as reference. Table 3 shows the water quality at influent and effluent of Truc Bach STP in which the influent measured on weekdays is used for comparison. 
Table 2 - Typical Vietnamese standards for surface water environment

\begin{tabular}{lccc}
\hline \multirow{2}{*}{ Parameters } & \multirow{2}{*}{ Unit } & \multicolumn{2}{c}{ Class } \\
\cline { 3 - 4 } & & $\mathrm{A}$ & $\mathrm{B}$ \\
\hline $\mathrm{BOD}_{5}\left(20^{0} \mathrm{C}\right)$ & $\mathrm{mg} / \mathrm{L}$ & $<4$ & $<25$ \\
$\mathrm{COD}$ & $\mathrm{mg} / \mathrm{L}$ & $<10$ & $<35$ \\
$\mathrm{SS}$ & $\mathrm{mg} / \mathrm{L}$ & 20 & 80 \\
Ammonia as N & $\mathrm{mg} / \mathrm{L}$ & 0.05 & 1 \\
Total coliform & $\mathrm{CFU} / \mathrm{mL}$ & 50 & 100
\end{tabular}

Note: A- For drinking water supply; B- For other purposes

Table 3 - Average water qualities of influent to Truc Bach STP

\begin{tabular}{|l|c|c|c|c|}
\hline & \multicolumn{2}{|c|}{$\begin{array}{c}\text { Measured values for STP } \\
\text { influent }\end{array}$} & \multicolumn{2}{c|}{ Design criteria } \\
\hline & Weekend & Weekday & Influent & Effluent \\
\hline COD (mg/L) & 196 & 222 & 225 & 35 \\
\hline SS (mg/L) & 364 & 531 & 180 & 20 \\
\hline T-P $(\mathrm{mg} / \mathrm{L})$ & 8.3 & 5.7 & 5 & 1 \\
\hline T-N $(\mathrm{mg} / \mathrm{L})$ & 81 & 37 & 40 & 15 \\
\hline E.coli $(\mathrm{CFU} / \mathrm{mL})$ & $3.4 \times 10^{4}$ & $3.3 \times 10^{4}$ & - & - \\
\hline TC $(\mathrm{CFU} / \mathrm{mL})$ & $2.5 \times 10^{5}$ & $11.2 \times 10^{5}$ & $10^{4}-10^{5}$ & $2.10^{2}$ \\
\hline
\end{tabular}

(-): no data

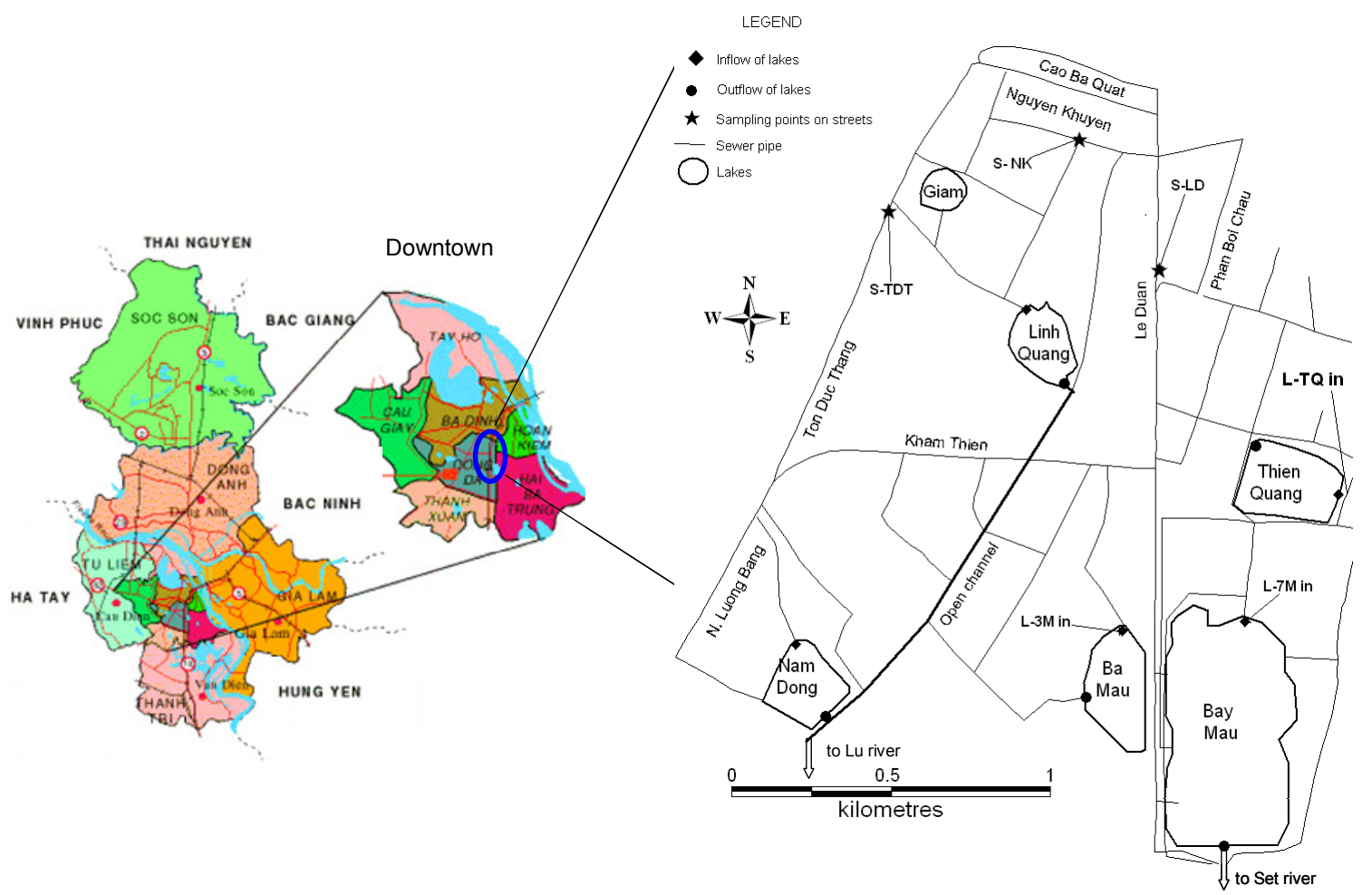

Fig. 3 - Wet weather sampling points on streets and lakes, 2008.

\section{RESULTS AND DISCUSSION}

\section{Time and Spatial Variation of Pollutant Concentration in Runoff Water}

Sampling results of runoff water quality at different places on a rainy day (August 31, 2008) are given in Fig. 4. Upon comparison with the Vietnamese standards, all 
parameters in the inflow samples did not meet the limit and total coliform was 2-3 logs higher. Even the coliforms (both T.coliform and E.coli) in road runoff samples, especially at S-TDT location, were higher than those in the inflow of lakes. This information should be considered when inundation takes place. All kinds of wastewater could possibly be mixed together and inundated water becomes a threat to human health due to exposure with pathogen.

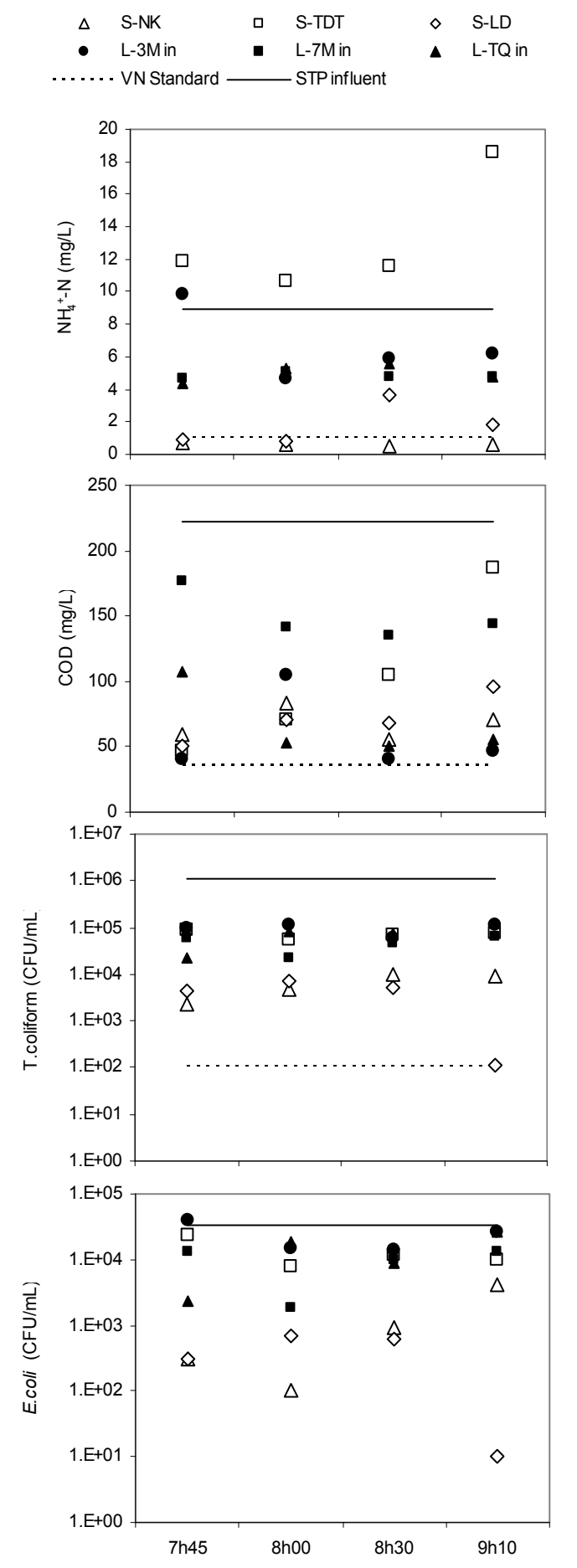

Fig. 4 - Pollutant concentration variation in runoff samples on August 31, 2008.
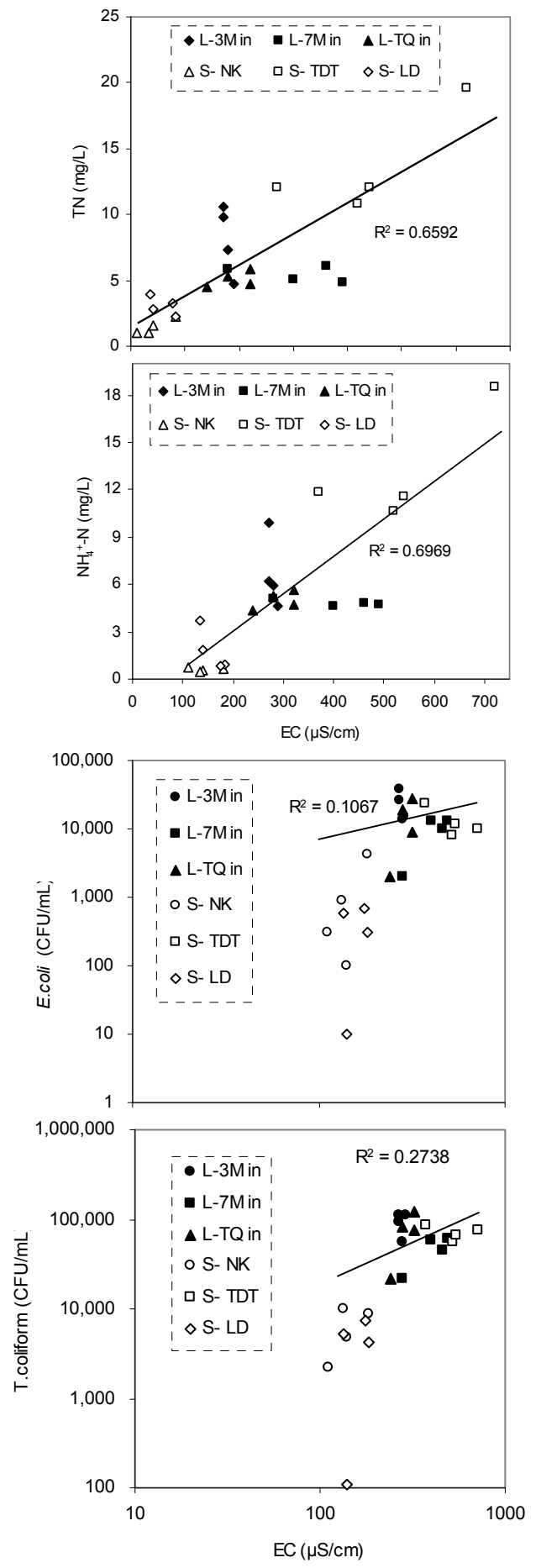

Fig. 5 - Parameter correlation with EC for samples taken on August 31, 2008. 
In road runoff samples, coliforms and $\mathrm{NH}_{4}{ }^{+}-\mathrm{N}$ concentration tend to increase at the end of rainfall. It may be due to less dilution with rainwater, however, EC also increases so the samples might be mixed with domestic wastewater which is discharged directly from individual households, as shown in Fig. 6.

Besides wash-off from surface, another pollutant source contributing to non-point pollution sources is domestic wastewater discharged from individual households, which were constructed after the sewerage system, by the streets in downtown Hanoi or due to the malfunctioning and overflowing of the septic systems. Although individual households might contribute only minor amounts of non-point pollution, the combined effect of an entire neighbourhood can be serious (US EPA, 2008).

Among the parameters, EC and DOC have the highest correlation with others (Taebi and Droste, 2004) and EC could be used as an indicator of mixing wastewater with runoff water. Fig. 5 shows the correlation of EC with T-N, $\mathrm{NH}_{4}{ }^{+}-\mathrm{N}$, E.coli and TC, in which the correlation of EC with T-N and $\mathrm{NH}_{4}{ }^{+}-\mathrm{N}$ is higher than that of the coliforms. The correlation between E.coli and TC with EC in road runoff samples is stronger than that of lakes. It may contribute to the variety of source contributions to water samples at the inflow of lakes such as from septic tank leakage.
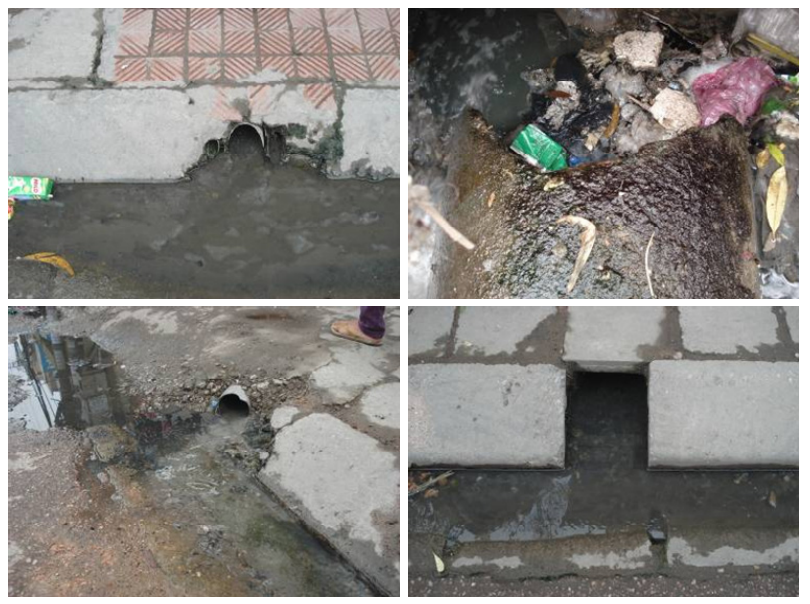

Fig. 6 - Domestic wastewater discharge from individual households.

Runoff water qualities collected on September 21, 2008 at the same locations were plotted together with the average runoff water quality on previous sampling, August 31, 2008, as shown in Fig. 7. In general, water quality in September is higher than that in August, although precipitation was lower and the duration was shorter. The trend of variation between sampling locations is still kept, and runoff water quality is much higher than the Vietnamese standard and close to the water quality of STP influent.

It was observed that the quality of surface runoff water had a vast range of variation which is far greater than that in the quality of raw or treated sanitary wastewater (Mitchell, 2005). This makes surface runoff quality control to be more difficult. 

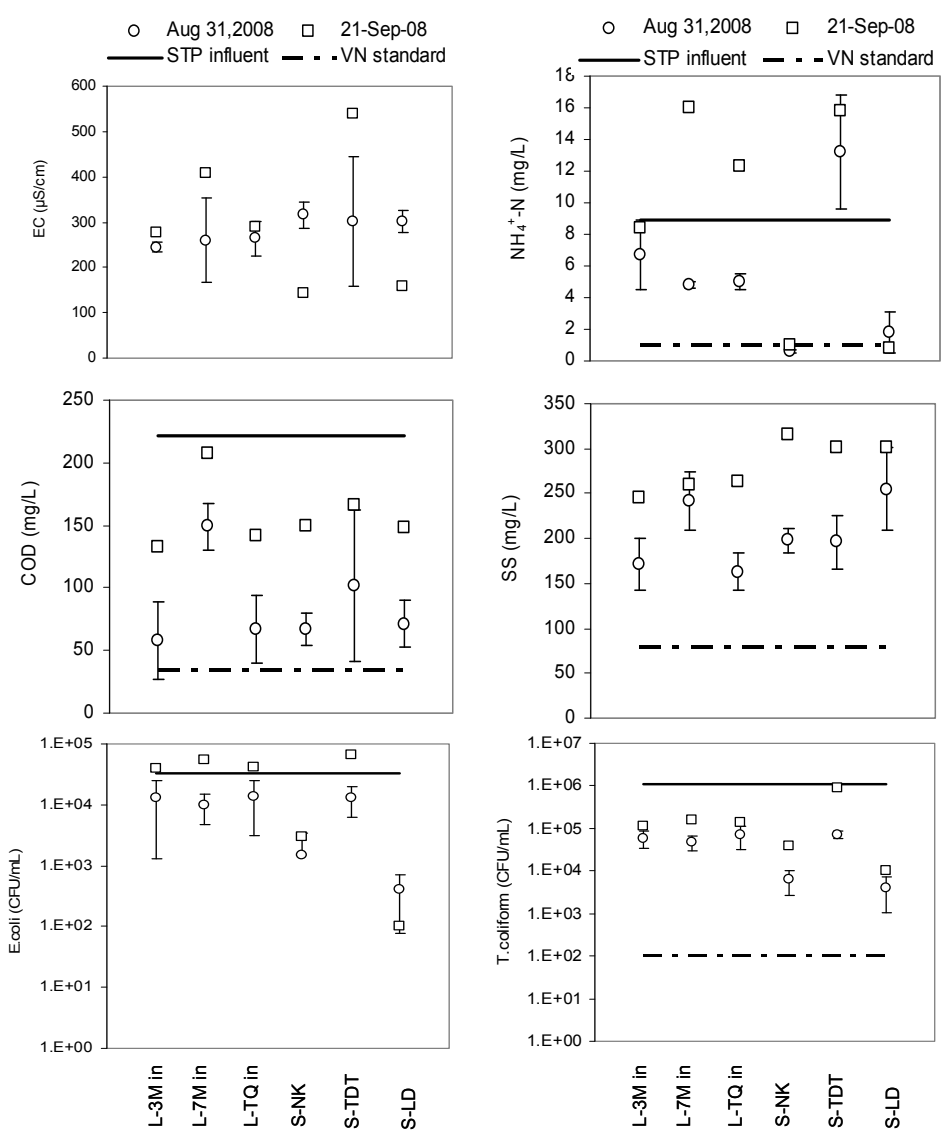

Fig. 7 - Average pollutant concentrations in samples.

\section{Similarity of Water Quality between Sampling Locations}

Water quality data were normalized and cluster analysis was used to find the spatial variation between sampling locations. Normalized data were used as input in cluster analysis, and coliform data were converted to logarithmic form. The sample locations are classified into several groups using cluster analysis by the Ward method with squared Euclidean distance. Four samples collected in August were named as A1-A4 while two samples collected in September were named as S1 and S2. Based on cluster analysis, sampling locations were classified into five groups using T-N, COD, SS, EC and TC parameters. The average water quality of each group is shown in Table 4. Dendrogram of similarity between sampling locations is shown in Fig. 8.

Group 1, with the least polluted samples including samples collected at two streets in August (S-LD and S-NK), had the lowest T-N, COD, EC and TC concentrations. This was road runoff group. Group 2, slightly polluted group, contained moderately polluted samples in August and slightly polluted samples in September, and had low T-N, EC and TC. Group 3, moderately polluted group, consisted of samples at the inflows of lakes (L-3M in, L-TQ in and S-TDT) collected in August, was characterized by medium ranking of T-N, EC, and TC concentration. Group 4, the highly polluted group including high-pollutant samples in August and medium pollutant concentration in September, was indicated by high value of T-N, COD, EC, and TC. Group 5, the most polluted group with the highest T-N, COD, SS and TC concentration, consisted of samples taken at L-3M in, L-7M in and S-TDT in September. 
Table 4 - Average water quality of each group

\begin{tabular}{lccccc}
\hline & $\mathrm{T}-\mathrm{N}[\mathrm{mg} / \mathrm{L}]$ & $\mathrm{COD}[\mathrm{mg} / \mathrm{L}]$ & $\mathrm{SS}[\mathrm{mg} / \mathrm{L}]$ & $\mathrm{EC}[\mu \mathrm{S} / \mathrm{cm}]$ & $\mathrm{TC}(\log )$ \\
\hline Group 1 & 2.3 & 69 & 227 & 150 & 3.73 \\
& $(1.0)$ & $(15)$ & $(44)$ & $(27)$ & $(0.64)$ \\
Group 2 & 8.1 & 141 & 272 & 200 & 4.59 \\
& $(7.4)$ & $(25)$ & $(83)$ & $(120)$ & $(0.44)$ \\
Group 3 & 8.0 & 48 & 155 & 301 & 4.95 \\
& $(2.9)$ & $(6)$ & $(6)$ & $(37)$ & $(0.11)$ \\
Group 4 & 19.2 & 139 & 228 & 531 & 4.95 \\
& $(14.1)$ & $(38)$ & $(27)$ & $(86)$ & $(0.21)$ \\
Group 5 & 59.9 & 166 & 274 & 457 & 5.65 \\
& $(30.8)$ & $(71)$ & $(81)$ & $(264)$ & $(0.50)$ \\
\hline
\end{tabular}

Note: (): Standard deviation

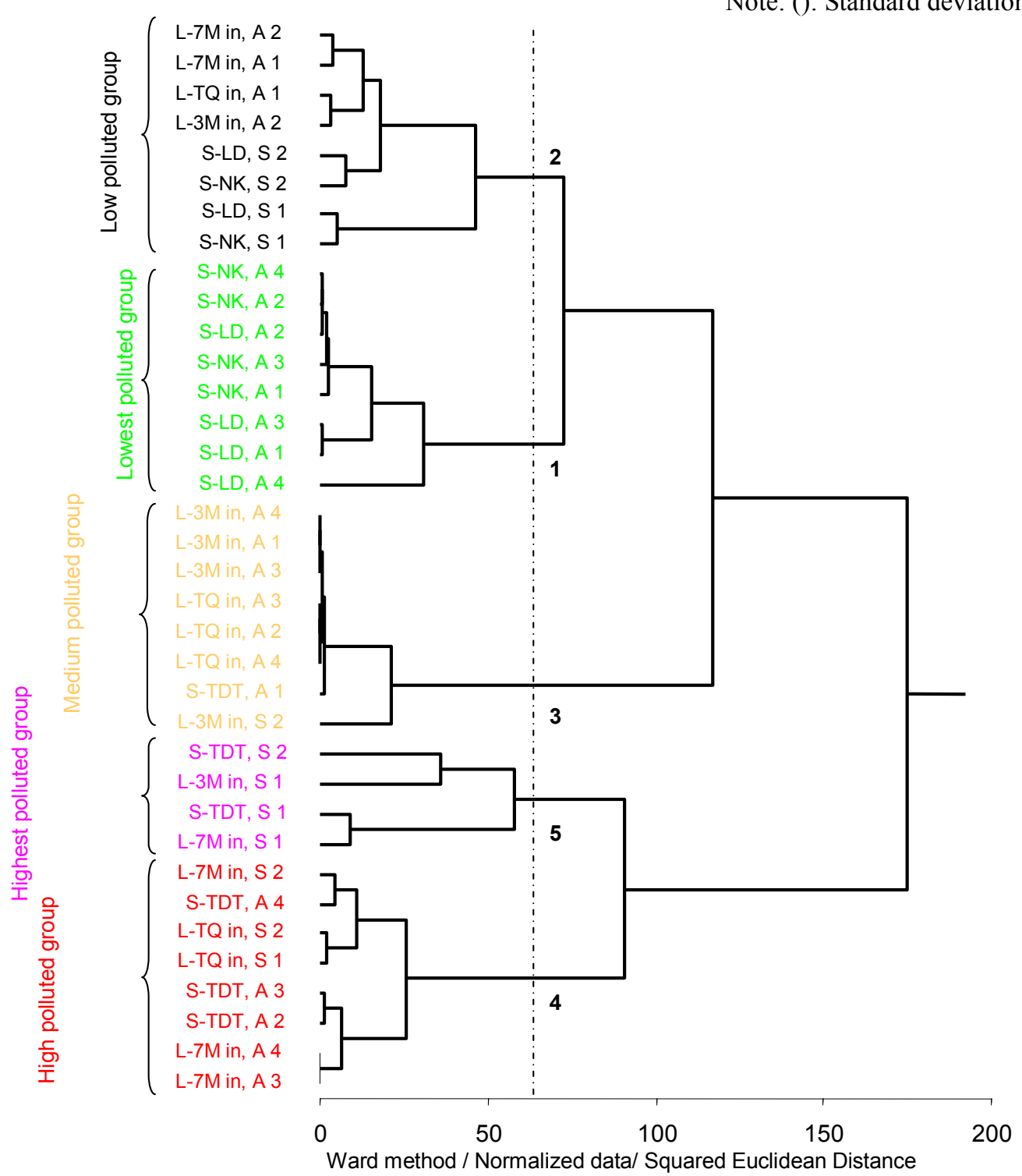

Fig. 8 - Similarities among sampling locations using T-N, COD, EC and TC parameters Samples collected in September show higher pollutant concentration due to short duration of rainfall, and the collected samples were affected by first-flush effect. Accumulative precipitation, which is lower than $8 \mathrm{~mm}$, is still in the range of first-flush effect (Maestre et al., 2004). 
In road runoff samples, sampling location at S-TDT showed high pollutant concentration in comparison with S-LD and S-NK due to S-TDT located in newly urbanized area without planning and control. In this area, sewerage system and sanitary facilities are not well constructed. The water quality at inflow of Linh Quang lake (Quan et al., 2008), which receives domestic wastewater from this area, as shown in Fig. 3 , also confirmed this observation.

\section{CONCLUSIONS}

Pollutant sources from surface washoff are different depending on the sampling locations and rainfall patterns. Time variation of pollutant concentration in road runoff showed increasing trend at the end of rainfall. This may be attributed to less dilution with rainwater, leaking from toilet system or direct discharge from individual households to the roadside in downtown area.

Pathogenic indicators as E.coli and TC showed high values when compared with the Vietnamese standards and quite close to the level of domestic wastewater at the influent of STP. The EC parameter shows high correlation with other paremeters, especially with $\mathrm{NH}_{4}{ }^{+} \mathrm{N}$ and coliforms. EC could be used as an indicator of mixing wastewater in water samples when collected under wet weather condition.

These results indicate the range of variation in the quality of surface runoff which makes urban surface runoff quality control more difficult. Besides washoff from the surface, another pollutant source contributing to non-point pollution sources in Hanoi is domestic wastewater discharged from individual households or the malfunctioning and overflowing of septic systems. Due to frequent inundation in Hanoi, this result is useful for local government and residents to mitigate the inundation impacts to human health.

\section{ACKNOWLEDGEMENTS}

The current study is partially performed with the financial support from the $21 \mathrm{st}$ Century Center of Excellence program on the "Center for Sustainabale Urban Regeneration (cSUR)", managed by the University of Tokyo. The authors are sincerely grateful to the Research Center for Environmental Technology and Sustainable Development, Hanoi University of Science, for its assistance during monitoring and sampling.

\section{REFERENCES}

Anh N. V, Nga P. T, Nhue T. H and Antoine M. (2005). The potential of decentralized wastewater management for sustainable development, A Vietnamese experience, WEF International Conference: Technology, August 2005, CA, USA .

Gruber G., Winkler S. and Pressl A. (2005). Continuous monitoring in sewer networks an approach for quantification of pollution loads from CSOs into surface water bodies. Water Science and Technology, 52 (12), 215-223.

Ha T. D. (2005). Trend of water quality in 05 lakes improved by Hanoi drainage project phase I and solutions, Report for Hanoi Drainage Projects, phase I.

Maestre A., Pitt R. and Williamson D. (2004). Nonparametric Statistical Tests 
Comparing First Flush and Composite Samples from the National Stormwater Quality Database. In Models and Applications to Urban Water Systems, Vol. 12. Computational Hydraulics Int., Guelph, Ontario. pp. 317-338.

Marsalek J. and Rochfort Q. (2004). Urban wet-weather flows: Sources of fecal contamination impacting on recreational waters and threatening drinking-water sources, Journal of Toxicology and Environmental Health-Part A-Current, 67(2022), 1765-1777.

Mitchell G. (2005). Mapping hazard from urban non-point pollution: a screening model to support sustainable urban drainage planning, Journal of Environmental Management, 74(1), 1-9

O'Keefe B., D'Arcy B. J., Davidson J., Barbarito B. and Clelland B. (2005). Urban diffuse sources of faecal indicators, Water Science and Technology, 51(3-4), 183190

Quan P. V., Thang V. Q., Ha B. T. T. and Thuy N. T. (2005). Study on decomposition speed constant $(\mathrm{k} 1)$ and BOD contamination level of some lakes in Hanoi. Vietnam Journal of Analytical Sciences in Physics, Chemistry, Biology, ISSN 08683224, T10, 56-61 (in Vietnamese).

Quan P. V., Furumai H., Kurisu F., and Kasuga I., (2008). Surface water pollution due to discharging from sewerage system in downtown of Hanoi. Proceeding of the 6 Southeast Asia Water Environments, Bandung, Indonesia, Nov 1-4, 2008: 223-233.

Taebi A. and Droste R. L. (2004). Pollution loads in urban runoff and sanitary wastewater, Science of the Total Environment, 327 (2004), 175-184.

Thang V. Q., Quan P. V., Hue N. T., Phuong T. T. T., Mai T. T. M., Thuy B. T., Tien D. D., Linh T. H. and Duc H. D. (2005). Water pollution and ecosystem protection in Hoankiem lake, Hanoi, Vietnam Journal of Analytical Sciences in Physics, Chemistry, Biology, ISSN 0868-3224, T10, $42-50$ (in Vietnamese).

US EPA (2008). Polluted runoff (Non point pollution source). http://www.epa.gov/owow/nps/ 